\title{
The use of web simulator as an auxiliary to the physical teaching: Concepts about electromagnetism in the distance education mode
}

\author{
Cairo Dias Barbosa, José Gidauto Dos Santos Lima Junior, Juliano Cordeiro Gallottes, \\ Luiz Moreira Gomes, Fernanda Carla Lima Ferreira
}

Department of Physics, Federal University of the South and Southeast of Pará, Marabá-PA, Brazil, 68500-000

\section{Email address:}

fernacarlaluan@gmail.com (F. C. L. Ferreira), cairodb@gmail.com (C. D. Barbosa), gidautojunior@gmail.com (J. G. S. Lima Junior), julianocgallotte@ hotmail.com (J. C. Gallottes) luizmg@ufpa.br (L. M. Gomes)

\section{To cite this article:}

Cairo Dias Barbosa, José Gidauto Dos Santos Lima Junior, Juliano Cordeiro Gallottes, Luiz Moreira Gomes, Fernanda Carla Lima Ferreira. The Use of Web Simulator as an Auxiliary to the Physical Teaching: Concepts about Electromagnetism in the Distance Education Mode. American Journal of Electromagnetics and Applications. Vol. 2, No. 4, 2014, pp. 34-38. doi: 10.11648/j.ajea.20140204.11

\begin{abstract}
The world is changing constantly and together with it education and its modalities, that is, the dimension that education develops it becomes necessary to comply with the new demands emerging from this development. The distance education is one of these developments in education system, with all the specifics, it's more than that, it is a window of opportunity that opens, allowing the population to achieve satisfactory educational levels, especially in a country of continental dimensions as Brazil. Ahead of this scene, it is observed a moment where the development of the Technologies of Information and Communication (ICT) never reached waited levels, proving the importance of distance education in our country. In this work, the contributions of ICT involved in teaching through the Web are presented, regarding particularly the use of virtual simulators in electromagnetism bases. The technological easinesses proportionated by the TIC enter in this modality of education as one of the main technologies directed to education in the distance and virtual simulation as one among some effective methodological tools in this education. The simulators are programs that simulate the behavior of physical systems from predetermined models. Simulation results are usually presented in large format visual appeal, as animations, graphs. Thus, little intuitive concepts and of difficult visualization as the concepts on Electromagnetism, become accessible the students. Currently, simulation programs are probably the most popular application way of computers to Physics teaching. A range of these programs is available on the Web in apllets's form written in Java ${ }^{\circledR}$, Flash ${ }^{\circledR}$ among others. In this paper, the electromagnetic simulations had limited to the use of on-line virtual platform available at htpps://phet.colorado.edu/pt_BR, in this interactive website, it's possible to select not only electromagnetism simulations, as well as in other Physics' areas offering to the students an extremely interactive environment of significant learning.
\end{abstract}

Keywords: Simulators, Teaching of Physics, Electromagnetism, Distance Education

\section{Introduction}

The physics is one of the areas of science where the individual needs different mediums and methodologies, so that a distinguished learning occurs. In this direction, the necessity of playful lessons becomes undoubted where students can live deeply of more concrete form the subject in study. In a virtual environment of learning, several media can offer this interactivity to the students, amongst them, the simulators. The use of Information and Communication Technologies (ICT) allows scientific knowledge be enhanced. The simulators show several advantages: they don't require physical space, some are free, they stimulate several senses, which facilitate effective learning, and also allow greater sharing of information [1].

This work comes to add to the existing bibliography concerning the application of this tool in the context of the education of Physics in courses of the modality, presenting some peculiarities and suggesting exploration ways of the same available resources. The use of simulators is in general justified for the fact of physics education to be judged by students as complex, having as consequences the difficulties in understanding of certain phenomena mainly the ones involving electromagnetism, whereas, on the other hand, 
simulators offer a species of support to the students, being able to facilitate the learning of the studied subject of more consistent form, beyond being an attractive factor and to bring on reflection.

It is verified that in contrast with what occurs in the instruction assisted by computer in the simulator, the student tends to keep an active position towards the simulation. Obviously, he expects to use the program to explore the physical model of its interest [1].

However, a problem with these simulators is observed, most of the time, the underlying physical model to the simulation cannot be modified by the student there. This limits the reach of investigations that can be made to the computer, "and if I change the model, what happens?" [2]. Another detected problem is that, in some cases, the student doesn't even realize that behind the simulation is a model and starts to see the program a substitute for to the experiment's accomplishments. It is obvious that a confusion between theory and reality can bring serious problems to the learning of physics (or the one of any other science), especially if education is in distance modality. But anyway, it must be recognized that simulation programs represent an advance in the use of computers as an innovative pedagogical tool, going beyond the book or virtual class [2].

It is believed, therefore, unanimously by the scientific community, that the insertion of new technologies, such as simulations contributes sufficiently by the student in the exploration of innumerable connections between basic scientific knowledge, natural phenomena and technological applications.

Thereby, the aim of the work was to accomplish a study about in the use of simulators inside innovative new technologies, in order to know its peculiarities and how to apply them in Physics area in distance courses.

Many researchers believe that simulations are considered the solution of some problems that physics teachers face when they try to explain physics to their student extremely abstract phenomena to be visualized through a description in words. They make it possible to observe in a few minutes the temporal evolution of a phenomenon that would take hours, days or years in real time, also allows the student to repeat the observation and whenever they want to modify its parameters or expand the many variables available in the physical phenomenon to be simulated [3].

There are others who claim that the simulation is to employ mathematical techniques in computers in order to imitate a process or an operation of the real world [4]. Moreover, they see the simulation with a broader view and believe that the simulation allows the student not only to handle the event but to know and modify it, making the relationships between the present physical greatnesses in the phenomenon.

As seen, in recent years, several authors had disclosed in favor of the use of simulators in computer simulations in physics teaching, however, for some scholars and researchers, the simulations present some disadvantages.

Modern computational techniques have transformed the visual representations and computer simulations easy and truly spectacular. To the same, however, they have created a dangerous trend of an exaggerated use of animations and simulations considering them as alternatives to real experiments, as if they had the same epistemological and educational [5] status.

\subsection{Interactive and Non-Interactive Simulations}

The simulations are classified in interactive and non-interactive. In interactive simulations, the students are able to modify several simulation parameters, exploring the physical situation by checking the implications of the modifications made in the behavior of the studied phenomenon [6]. However, in the non-interactive simulations, the user can't modify any parameters of the simulation [3].

\subsection{The Simulator and the Process of Teaching-Learning}

According Freire (1996) "to teach is not to transfer knowledge but to create the possibilities for the production or construction" [7].

The student cannot be seen only as a receiver but as an individual who interfere, manipulate, re-invents. So from this perspective the role of the teacher becomes the coordinator of work teams, a facilitator should make use of the new technologies that emerge in order to improve their work, for example, the simulator that provides interactivity with the student information [8].

The theory of learning by discovery supports active learning, requiring explorations and discoveries effective for achieving a true understanding. Assuming therefore that the exercise procedural and procedural capabilities relative to the scientific method, the student develops surely thought, especially as it starts to grasp by understanding, not by memorizing [9].

Analyzing the learning theories of Vygotsky, one realizes also that the use of simulators is perfectly consistent with what the author argues about the acquisition of knowledge. The simulator presents the information through the signs (symbolic language), provides the interaction with the content studied and it can be worked in the Zone of Proximal Development (ZPD) of the student, as based on the actual developmental level of the learner and through instruction given by the teacher, by hand or even through internet searches regarding the use of the program, the student can handle the simulator and thus take possession of new knowledge [10].

The teaching-learning becomes more effective if the use of simulators is not just an accessory, being incorporated into the teaching activity as a didactic element. In this way, the teacher will be able to elaborate activities so that to answer the questions, the students have to interact with the simulation, taking advantage of the main benefits of its use, as animation and interaction.

The simulations can be used to finalize a topic, so that the possible defect in the understanding of the concepts can be rectified and be cured.

It is worth mentioning that it is the teacher / tutor to 
elaborate activities duly substantiated in script allowing the students to use the simulators safely, following step by step the teacher/tutor's pre-established script.

\subsection{The Playful Character of the Simulator in the Learning of Laws and Physical Concepts}

As the laws of physics can be expressed through formulas, such software simulators obtain to create ambience very close to the reality, and through these, it becomes possible to simulate different physical phenomena such as, for example, the free fall of an object, the dilation a gas, a liquid pressure etc. The simulators also present the advantage of being able to realize experiments that outside the virtual world are very dangerous and possess a high cost [11].

There is still the advantage of allowing the student the access to such tool from any computer that has this application installed or via the internet, enabling the student not to stay entailed only to the didactic material of the institution of education for the accomplishment of its experiments.

It is likely that the simulator among the new technologies used in distance education in the teaching of physics, is a tool that provides a more playful way of learning because it allows a great student interaction with the content being studied. This feature puts the student as a controller of situations that imitate or approach to reality, which allows the student to somehow have mastery over the process of teaching and learning [12].

The differential of the simulator over other technologies is the playful and dynamic character this tool has, because the student, by means of it, gets variable control determining the behavior of a studied phenomenon, taking the student to think on the modifications in the results and therefore learn through discovery.

In this way, dealing with interactive simulations, the students can measure and control entrance parameters such as position measurements, electric current, electric field vector, boundary conditions, temperature and thus to observe the modifications that are succeeded [11].

\subsection{The use of Simulators in the Comprehension Electromagnetic Phenomena}

One of the main difficulties in teaching electromagnetism is due to the matter of magnetic concept field and the electric charges movement.

Due to the abstraction of these concepts, the student can create sometimes erroneous interpretations of laws and studied physics concepts.

Based on these difficulties, the simulators are great technological resources that can contribute so that students can better understand the characteristics of a magnetic field, and which its relationship to the electric charges movement, beyond taking them to a better mathematical formula understanding that the electromagnetism study involves.

\section{Discussion}

In this paper, we present some virtual simulations that served as the understanding of some physical concepts applied to electromagnetism. As mentioned earlier, we used the virtual simulator of the web portal htpp: //phet.colorado.edu/pt_BR/.

The Physics Education Technology (PhETTM) is a project of the University of Colorado of the United States of America - owner of the brand, designed to develop simulations of high quality, not only in the physical area as in other areas of science.

In the PhETTM's portal, simulations are available in Portuguese that can be twirled online or downloaded for free by students, teachers or even curious people. An aspect that deserves prominence in this portal is the easy access and the ability to run simulations on any device without the need of highly specific resources - usually, they are developed in Java ${ }^{\circledR}$ and Flash ${ }^{\circledR}$ and can be performed using any browser web, since these programs are already installed.

\subsection{Simulations}

In this simulation the student will be able to manipulate variables such as magnetic field strength, the spacing and sizes of needles representing the magnetic field, disposal the compass or bar magnet in different positions, that the compass needle by it is a small magnet, with this to observe the needle of the compass, to be about a small magnet, is if guiding in accordance with the magnetic field of the bar magnet. The simulator still provides a good idea of the direction of the lines of induction of one pole to the other pole of the magnet.

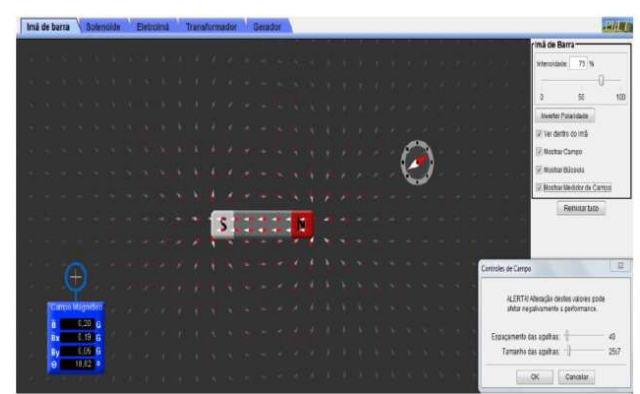

Figure 1. Simulation where you can check the vectors of electromagnetic induction of a bar magnet [13].

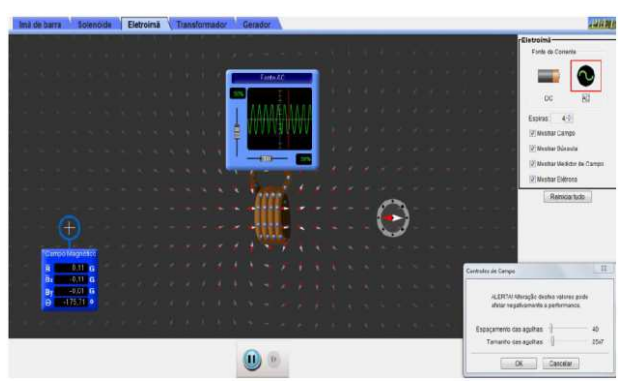

Figure 2. Simulation of an electromagnet where one can change the electric current, the amount of solenoids and other variables [13].

In Figure's simulation 2, the student may find that a solenoid, as well as any metal conductor traversed by an electric current generates magnetic field. It will be able to 
choose the type of electric current to be used in the circuit is alternating or continues. To observe that the compass needle is oriented according to the lines of magnetic induction generated by the electrical current in the solenoid, in the case of alternating current, as the direction of the electrons are always inverting consequently the field is changing its direction, and the needle of the compass tends to accompany this change.

This simulation shows that actions exerted by magnetic fields can produce electric current, that is, simulation assists in the understanding of the phenomenon of electromagnetic induction. The student, through the manipulation of the simulator, will be able to find out that when moving inside a solenoid, a magnet or an electric current in a closed circuit, both will produce an electric current in the solenoid circuit, which can be featured in the light bulb that will be lit in virtue of the produced electric current.

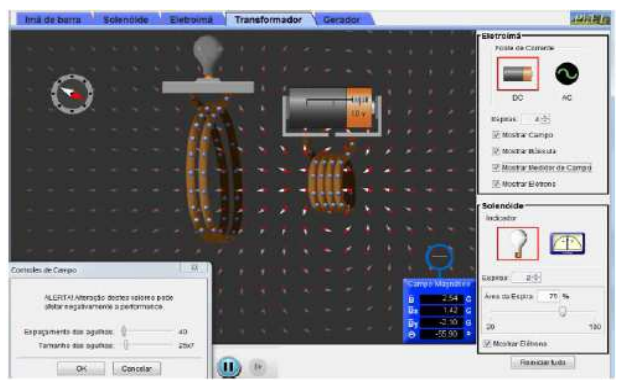

Figure 3. Simulation of a transformer and the production of electric current in the solenoid [13].

The simulation of Figure 4 presents a very playful character, because it shows the production of electric current through the potential energy of water. With this tool, students will be able, for example, to have an idea of how the production of electricity in a hydroelectric plant occurs.

When turning on the tap system, the student will notice that the force of the water spins the magnet that is attached to a waterwheel. With this, the magnetic field of the magnet is moving regarding the solenoid circuit, and this movement causes an alternating current that can be verified by the lamp that lights up and the movement of the compass needle, which is oriented according to the field magnetic magnet.

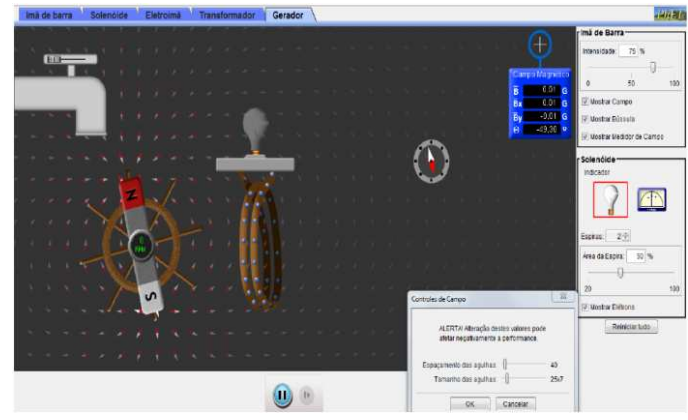

Figure 4. Simulation of an electric generator in the presence of a potential difference associated with waterfall faucet [13].

In this simulation, the student will still be able to see the change in the direction of moving electrons and the variation in the line of magnetic field induction.

\section{Final Considerations}

The purpose of this study was to show that the use of new Information Technology and Communication (ICT) in education, specifically the use of simulators in teaching electromagnetism to students in the distance education mode, causes reflections on the current teaching, enabling physics classes, even in the distance modality, much more pleasant

The learning platform with just texts, tasks and lists of exercises are not guarantees of a good learning environment must first be exciting, enjoyable and interactive. The contents of physics for students in distance education mode should be approached in a diversified manner, ie, through pictures, videos, games and simulators. After all, and in the virtual learning environment that these students spent much of the time, so should work with elements that stimulate and support the construction of knowledge by the student.

Notably, it is to notice that knowledge advances towards a dynamic learning process and this process has as a common characteristic to provide the access to the information available on the web equally and not restricted to an only group of individuals.

Among the various possibilities of the use of computer science in teaching physics, the use of computational simulations was opted, to believe that this enriches the interaction of the students with the process of construction and analysis of scientific knowledge, this way allows them to understand better the physical models.

The simulations must be chosen based on the presupposed of that, to obtain good learning, student engagement must be active; applications must be useful in different ways and depending on the aims of the activities, interactivity starts to be an essential characteristic.

It should be great to remember that the teacher / tutor must always be careful to make clear to students that the simulations reproduce the reality in a schematic and simplified way and experiments accomplished by means of simulations aren't equivalent to real ones. Activities must be done so that the student doesn't lose sight of the exploited physical meaning, avoiding using simulations as simple entertainment.

Although its great efficiency as it was discussed in this paper about the concepts of electromagnetism, it's noteworthy that simulations must be used as an additional resource in the teaching process whatever it is present or distance, and it's up to the teacher / tutor to establish roadmaps of activities in order to facilitate a safe learning of the contents studied.

\section{References}

[1] C. B. VALENTINI; SOARES, E. M. S. Aprendizagem ambientes virtuais compartilhando ideias e construindo cenários. $2^{\text {a }}$ Ed. Educs, 2010. 
[2] CEDERJ. Informática para o ensino de Física. Computadores no ensino de Física. Rio de Janeiro, 2013. Disponível em htpp://www.matfis.com.br/material. Acesso em 10 de jul. de 2013.

[3] V. HECKLER; M. F. O SARAIVA; K. S. O. FILHO. Uso de simuladores, imagens e animações como ferramentas auxiliares no ensino/aprendizagem de óptica. Revista Brasileira de Ensino de Física, v. 29, n. 2, 2007, pp. 267-273.

[4] P. J. FREITAS FILHO. Introdução à modelagem e simulação de sistemas: com aplicações em arena. 2. ed. Florianópolis: Visual Books Ltda., 2008.

[5] A. MEDEIROS; C. F. MEDEIROS. Possibilidades e limitações das simulações computacionais no ensino da física. Revista Brasileira de Ensino de Física, São Paulo, v. 24, n. 2, 2002, pp. 77-86.

[6] R. O. COELHO. O uso da informática no ensino de física de nível médio. 101 f. Dissertação (Mestrado em Educação) Faculdade de Educação da Universidade Federal de Pelotas, UFPel, Pelotas, 2002.

[7] P. FREIRE. Pedagogia da Autonomia: Saberes necessários a prática Educativa. Disponível em: < TTP://www.letras.ufmg.br/espanhol/pdf\%5Cpedagogia_da autonomia_-_paulofreire.pdf $>$. Acesso em 14 de nov. de 2014.
[8] M. T. A. FREITAS. História da Pedagogia: A Perspectiva Vigotskiana e as Tecnologias. Revista Educação. São Paulo, v. 2, 2010, pp. 58-67.

[9] C. VASCONCELOS; J. F. PRAIA; L. S. ALMEIDA Teorias de Aprendizagem e o Ensino/Aprendizagem das Ciências: da Instrução à Aprendizagem. 2003. Disponível em: $\langle$ http://www.scielo.br/pdf/pee/v7n1/v7n1a02.pdf $\rangle$. Acesso em 10 de jun. de 2013.

[10] L. S. VYGOTSKY. A Formação Social da Mente.7 ed. São Paulo: Martins Fontes, 2007.

[11] C. FIOLHAIS; J. TRINDADE. Física no Computador: o Computador como uma Ferramenta no Ensino e na Aprendizagem das Ciências Físicas. Revista Brasileira de Ensino de Física, v. 25, n. 3, 2003, pp. 259-272. Available in http://www.sbfisica.org.br/rbef/pdf/ v25_259.pdf. Access in 2013.

[12] R. OLIVEIRA. Informática educativa: Dos planos e discursos à sala de aula. 15. Ed. Campinas (SP): Papirus, 1997.

[13] Phet interactive simulations. Available in https://phet.colorado.edu/pt_BR/. Access in 2014. 